\title{
A relevância dos temas Inovação e Qualidade na pesquisa Contábil: Um estudo bibliométrico em eventos científicos no Brasil
}

\author{
Jacquelline Aparecida Batista de Andrade \\ Mestrado em Administração pela Faculdade Novos Horizontes - Unihorizontes \\ Av. Cula Mangabeira, 210, S 424. Bairro Santo Expedito. Montes Claros/MG \\ E-mail: diretoria@jjcontabilidade.com.br \\ Cristiana Fernandes de Muÿlder \\ Doutorado em Economia Aplicada pela Universidade Federal de Viçosa - UFV \\ Doutora do corpo permanente da Universidade FUMEC \\ Av. Afonso Pena, 3.880. Belo Horizonte/MG \\ E-mail: cristiana.muylder@fumec.br
}

\section{RESUMO}

Os estudos bibliométricos em Contabilidade têm possibilitado a disseminação da discussão acadêmica acerca da sua evolução, permitindo mapear e analisar a qualidade da produção científica brasileira, propondo uma reflexão sobre a área em questão. Valendo-se da bibliometria como ferramenta estatística de pesquisa, este artigo tem como principal objetivo verificar a inserção dos temas Inovação e Qualidade na área contábil e sua evolução no meio acadêmico. O estudo foi realizado nos trabalhos científicos apresentados no $17^{\circ}$ e $18^{\circ}$ Congresso Brasileiro de Contabilidade (CBC), em 2004 e 2008 e nos Encontros da ANPAD de 2007 e 2008, na área específica de contabilidade. A pesquisa revela a existência de estudos sobre qualidade e inovação nesta área, com uma concentração bem maior do termo qualidade, enquanto o tema inovação ainda é pouco explorado. De 2.493 citações registradas no $17^{\circ} \mathrm{CBC}, 2.369$ mencionam o termo qualidade. Em 2008, $77,78 \%$ dos 99 trabalhos apresentados no $18^{\circ}$ CBC citam qualidade, com predominância para os artigos dos estados da Região Sul. A análise dos EnANPADs 2007 e 2008, revela que 10\% de toda a produção acadêmica deste evento compreende a área das Ciências Contábeis, com enfoque mais específico na contabilidade gerencial, apontando para uma uniformidade das citações por artigo.

Palavras-chave: Inovação. Qualidade. Contabilidade.

Innovation and Quality relevance in a bibliometric research of accounting area in Brazilian scientific events 
A relevância dos temas Inovação e Qualidade na pesquisa Contábil: Um estudo bibliométrico em eventos científicos no Brasil Jacquelline Aparecida Batista de Andrade, Cristiana Fernandes de Muÿlder

\section{ABSTRACT}

Bibliometric studies in accounting have facilitated the dissemination of academic discussion about the evolution of this, analyzing the quality of Brazilian scientific production, offering a reflection of the area. Drawing up of bibliometrics as a tool for statistical research, this article has as main objective to verify the integration of innovation and quality issues in accounting and its development in academic area. The basis of this study was the 17th and 18th Brazilian Congress of Accounting (CBC) realized in 2004 and 2008, and the Enanpad specific accounting area, which occurred in 2007 and 2008. The research shows that the theme quality is more related then innovation theme in this specific accounting area. From 2,493 citations recorded in the 17th CBC, 2369 mention the term quality. In 2008, 77.78\% of the 99 papers presented at the 18th CBC mentioned quality and they are from brazilian south states predominantly. When the analysis was the Enanpad, just $10 \%$ of the academic production of this event includes area of Accounting Sciences, with more specific focus on management accounting and with similar frequencies.

Keywords: Innovation. Quality. Accounting.

\section{INTRODUÇÃO}

A competitividade entre as organizações modernas tornou-se uma questão básica de sobrevivência e, diante destes mercados altamente concorridos, as empresas passaram a valorizar um recurso primordial à sua sobrevivência: a contabilidade, uma ciência social capaz de prover aos seus usuários informações úteis e necessárias ao processo de tomada de decisões, tornando-se uma importante ferramenta de decisão gerencial.

Assim, percebe-se uma demanda por uma contabilidade mais sofisticada, em consonância com ritmo e padrões internacionais que asseguram a qualidade dos serviços, baseada na capacidade de inovar e na rapidez de obtenção de respostas, indicadores sobre os quais as organizações baseiam suas ações presentes e futuras.

Toda a atividade de inovação quer no setor de serviços, ou em qualquer outro setor da economia, têm como objetivo desenvolver novos processos/produtos, novos métodos e com padrões de qualidade definidos. Por qualidade entende-se a adequação ao uso das características de produtos que buscam atender as necessidades dos clientes e também da inexistência de defeitos ou deficiência (JURAN, 1990). 
A relevância dos temas Inovação e Qualidade na pesquisa Contábil: Um estudo bibliométrico em eventos científicos no Brasil Jacquelline Aparecida Batista de Andrade, Cristiana Fernandes de Muÿlder

Parasuraman et al. (1985) ressaltam que um serviço de qualidade é aquele em que as expectativas do consumidor sejam atendidas ou superadas. A contabilidade, portanto, necessita adequar-se às exigências do mercado e inovar seus processos e serviços bem como basear-se em qualidade na prestação dos serviços.

Diante do exposto, é de suma importância o olhar atento à discussão acadêmica acerca da evolução da contabilidade no Brasil, levantando evidências, tendências e potencialidades, possibilitando uma reflexão sobre as publicações nesta área de artigos em anais de congressos e em periódicos.

Nas últimas décadas já estão mais recorrentes os estudos bibliométricos em Contabilidade no sentido de mapear e analisar a qualidade da produção científica contábil nacional, propondo uma reflexão da área em questão.

Autores nacionais como Cardoso et al (2004), Cardoso et al. (2005), Martins e Silva (2005), Leite Filho (2005), entre outros, publicaram estudos em que analisam a produção acadêmica no sentido de contribuir para o desenvolvimento da qualidade dos trabalhos publicados e para a disseminação das informações neles contidas.

Sendo assim, este trabalho desenvolvido no cenário apresentado, tem como principal objetivo verificar a inserção dos temas Inovação e Qualidade na área contábil e sua evolução no meio acadêmico. Especificamente, é analisada a ocorrência destes dois termos nos trabalhos científicos apresentados nos Congressos Brasileiros de Contabilidade de 2004 e 2008 e nas edições de 2007 e 2008 do Encontro Nacional da Associação Nacional de Pós-Graduação e Pesquisa em Administração - EnANPAD, na área específica de Contabilidade.

A principal relevância deste estudo é aproximar as abordagens científicas às demandas das organizações neste contexto, onde a área contábil é foco de análise e aprimoramento contínuo. 
A relevância dos temas Inovação e Qualidade na pesquisa Contábil: Um estudo bibliométrico em eventos científicos no Brasil Jacquelline Aparecida Batista de Andrade, Cristiana Fernandes de Muÿlder

\section{REFERENCIAL TEÓRICO}

A área de contabilidade tem evoluído significativamente nos últimos anos em decorrência das mudanças econômicas, políticas, sociais, legais e regulatórias, que produzem um impacto nas organizações e na sociedade em geral.

No campo acadêmico a discussão da produção do conhecimento tem se intensificado em resposta a esta demanda das universidades. A pesquisa de Theóphilo e ludícibus (2005) aponta para uma melhoria na qualidade dos trabalhos com uma notável mudança de estudos teóricos para estudos teórico-empíricos, apesar da necessidade de maior diversidade de abordagens metodológicas.

Continuando o interesse no desenvolvimento da produção científica gerada em Contabilidade, Martins e Silva (2005) analisaram as referências bibliográficas de Congressos da área de Contabilidade de 2003 e 2004, e Silva et al. (2005) estudaram por meio da comparabilidade um periódico da área de Contabilidade no Brasil.

$\mathrm{O}$ crescimento de estudos bibliométricos tem demonstrado o amadurecimento e a diversificação da produção científica em contabilidade nos últimos anos. Recentemente, Faro e Silva (2008) mapearam a pesquisa em Contabilidade Gerencial de 1997 a 2007 nos principais periódicos internacionais, enquanto Gomes et al. (2008) evidenciaram as principais características dos artigos de Contabilidade Pública nos últimos três anos, apresentados em dois fóruns acadêmicos de respeitabilidade nacional: o EnANPAD e o Congresso USP de Controladoria e Contabilidade.

Dentre todas estas análises de produções científicas, atribuídas à importância do desenvolvimento científico, Cunha et al. (2008) propuseram investigar as evidências que permitissem avaliar o grau de disseminação das teses de doutoramento em Ciências Contábeis defendidas no país, na produção de novos conhecimentos.

Neste contexto de discussão pela busca de vantagens competitivas, principalmente no campo da administração e da contabilidade, o setor educacional começa a sentir os efeitos das mudanças dos processos organizacionais, atualmente voltados à qualidade e inovação impostas pelas novas tecnologias, novos sistemas, 
A relevância dos temas Inovação e Qualidade na pesquisa Contábil: Um estudo bibliométrico em eventos científicos no Brasil

Jacquelline Aparecida Batista de Andrade, Cristiana Fernandes de Muÿlder

novos serviços e formas organizacionais. A inovação remete os estudiosos e profissionais a novas idéias e a criação de oportunidades que possam efetivamente oferecer vantagens competitivas na formação das organizações deste novo século.

Apesar dos estudos sobre inovação não serem recentes, existe ainda hoje uma dificuldade para definir o que é inovação, uma vez que ela pode ocorrer em relação ao produto, ao processo tecnológico, à estrutura administrativa ou ao programa relacionado com os membros da organização (PERIN et al., 2007).

Schumpeter (1982) destaca que a inovação pode assumir várias formas; não sendo necessário criar algo novo, podendo mesmo submeter uma idéia já existente a uma nova forma de realizá-la ou uma nova situação.

$\mathrm{Na}$ definição de Moreira e Queiroz (2006), a inovação se apresenta como o processo pelo qual as organizações utilizam suas capacitações e seus recursos para desenvolver novos produtos, serviços, sistemas (operacionais ou de produção), formas de trabalho e tecnologias para melhor atender às demandas de seus consumidores.

Por outro lado, a qualidade da informação e dos serviços contábeis a serem desempenhados tem sido objeto de intermináveis debates na literatura do ensino e da pesquisa em contabilidade, demonstrando o interesse e a importância de prover os usuários da contabilidade de informações que sejam realmente úteis e necessárias na tomada de decisões.

Nos últimos tempos, o conceito de qualidade tem evoluído até reconhecer a importância de satisfazer muitos detentores de participação numa organização, incluindo a comunidade, os fornecedores, os acionistas, os empregados e a gerência. Atualmente, este construto abrange elementos tão diferenciados, como a melhoria de vida no trabalho, a promoção da diversificação de funções, a melhoria das condições ambientais, a facilitação das transações comerciais e o realce da competitividade (CHRISTO, 2001).

Notadamente, as atividades relacionadas com a qualidade se ampliam e são consideradas essenciais para o sucesso estratégico de qualquer instituição. Isso leva a uma percepção dinâmica e mais abrangente da qualidade, sinalizando a integração 
A relevância dos temas Inovação e Qualidade na pesquisa Contábil: Um estudo bibliométrico em eventos científicos no Brasil

Jacquelline Aparecida Batista de Andrade, Cristiana Fernandes de Muÿlder

com diversas outras áreas do conhecimento humano, em função do tipo de produto gerado e das expectativas, exigências e maturidade dos clientes e consumidores, em sintonia com os interesses mercadológicos estabelecidos (MARSHALL JUNIOR et al., 2005).

$\mathrm{Na}$ área contábil, a qualidade baseada na percepção do usuário da informação tem sido o enfoque mais aceito atualmente. Sob esta perspectiva, inovação e qualidade se juntam como um novo conhecimento, para produzirem as melhores práticas de informações gerenciais, sustentadas pela contabilidade, com o objetivo de promover o crescimento das organizações e o aprimoramento dos seus capitais físico, humano, social e ambiental, além de contribuir para que as empresas alcancem os níveis de produtividade e rentabilidade almejados.

\section{METODOLOGIA DA PESQUISA}

Para Martins e Theóphilo (2007), um problema de pesquisa origina-se da inquietação, da dúvida, da hesitação, da perplexidade, da curiosidade sobre uma questão não resolvida. A sua formulação depende da fundamentação teóricometodológica que orienta o pesquisador, assumindo o grau de abrangência em cada caso.

Desta forma, neste estudo se investiga as temáticas da qualidade e inovação, buscando atender aos objetivos propostos, com a realização de uma pesquisa bibliométrica, que segundo Guedes e Borschiver (2005, p.1), é "uma ferramenta estatística básica, utilizada na gestão da informação e do conhecimento científico e tecnológico". Na concepção de Macias-Chapula (1998), em tudo que se refere à ciência, a bibliometria torna-se essencial, uma vez que permite quantificar os aspectos da produção, disseminação e uso da informação registrada.

Para Araújo (2006), dentro da bibliometria, particularmente a análise de citações, permite a identificação e descrição de uma série de padrões na produção do conhecimento científico, uma vez que investiga as relações entre os documentos 
A relevância dos temas Inovação e Qualidade na pesquisa Contábil: Um estudo bibliométrico em eventos científicos no Brasil Jacquelline Aparecida Batista de Andrade, Cristiana Fernandes de Muÿlder

citantes e os documentos citados, considerados como unidade de análise, no todo ou em suas diversas partes.

O estudo também se enquadra no nível de pesquisa exploratória, que no entendimento de Andrade (2006, p.124), "é aquela que busca maiores informações sobre um determinado assunto", e sob a ótica de Gil (2007, p. 43), "tem como principal finalidade desenvolver, esclarecer e modificar conceitos e idéias, tendo em vista, a formulação de problemas mais precisos ou hipóteses pesquisáveis para estudo posteriores".

Devido à característica da pesquisa, depois de selecionados os artigos relacionados à área da contabilidade nos Congressos Brasileiros de Contabilidade de 2004 e 2008 e nos EnANPADs de 2007 e 2008 (Ensino e Pesquisa em Contabilidade, Contabilidade para Usuários Externos e Contabilidade Gerencial), foram feitos os levantamentos dos termos inovação e qualidade nos referidos artigos, buscando verificar a quantidade de inserções dos mesmos na literatura científico-acadêmica. Estes dois eventos foram escolhidos devido a sua importância no meio acadêmico no que se refere especificamente à publicação de artigos em construção e apresentação de pesquisas da pós-graduação no Brasil na área de Gestão e Contabilidade.

$\mathrm{Na}$ análise dos artigos apresentados, em função da natureza das informações, dos dados e das evidências levantadas, a investigação tem uma abordagem quantitativa, que conforme Martins e Theóphilo (2007) têm como função organizar, sumarizar, caracterizar e interpretar os dados numéricos coletados.

\section{APRESENTAÇÃO E ANÁLISE DOS DADOS DA PESQUISA}

Inicialmente optou-se em estruturar um banco de dados em planilha MS Excel por meio de uma Tabela, de todos os artigos publicados em anais do $17^{\circ}$ e $18^{\circ}$ Congresso Brasileiro de Contabilidade realizados em 2004 e 2008, bem como dos artigos que tivessem enfoque específico na área temática em Contabilidade e Ensino e Pesquisa em Contabilidade, publicados nos anais do EnANPAD de 2007 e 2008, 
A relevância dos temas Inovação e Qualidade na pesquisa Contábil: Um estudo bibliométrico em eventos científicos no Brasil Jacquelline Aparecida Batista de Andrade, Cristiana Fernandes de Muÿlder

levantado através de busca interna nos arquivos do programa Adobe Acrobat Reader as ocorrências ou não das palavras Inovação e Qualidade.

\subsection{7 $\mathrm{CBC}$ - Congresso Brasileiro de Contabilidade de 2004}

Realizado em Santos - SP, com debates sobre as questões que norteiam a profissão contábil, estabelecendo as tendências, os desafios, a responsabilidade profissional e a inserção do contabilista na sociedade, o $17^{\circ} \mathrm{CBC}$ com o lema "Contabilidade - instrumento de Cidadania", foi agrupado em 10 temas conforme se observa na Tabela 1.

Tabela 1 - Número de Citações por Temário Geral

\begin{tabular}{|c|c|c|c|c|c|}
\hline & \multirow{3}{*}{ TEMÁRIO GERAL } & \multirow{2}{*}{\multicolumn{4}{|c|}{$\begin{array}{l}\text { 17ㅇ CBC - } 2004 \\
\text { № de Citações }\end{array}$}} \\
\hline & & & & & \\
\hline & & Inovação & $\%$ & Qualidade & $\%$ \\
\hline Tema1 & Educação como Fator de Competência Profissional & 25 & 20,16 & 263 & 11,10 \\
\hline Tema2 & A Contabilidade e a Governança Corporativa & 4 & 3,23 & 92 & 3,88 \\
\hline Tema3 & NBC - Harmonização Internacional & 0 & 0,00 & 93 & 3,93 \\
\hline Tema4 & A Contabilidade e a Responsabilidade Social & 6 & 4,84 & 165 & 6,96 \\
\hline Tema5 & A Contabilidade e o Setor Público & 6 & 4,84 & 111 & 4,69 \\
\hline Tema6 & A Contabilidade na Era Digital & 2 & 1,61 & 41 & 1,73 \\
\hline Tema7 & O Processo de Comunicação das Informações Contábeis & 22 & 17,74 & 162 & 6,84 \\
\hline Tema8 & A contabilidade e o Sistema Tributário & 0 & 0,00 & 11 & 0,46 \\
\hline Tema9 & Contabilidade - Conflito de Interesses e Independência & 5 & 4,03 & 101 & 4,26 \\
\hline \multirow[t]{2}{*}{ Tema10 } & Tema Livre & 54 & 43,55 & 1330 & 56,14 \\
\hline & TOTAL GERAL & 124 & 100,00 & 2369 & 100,00 \\
\hline
\end{tabular}

Fonte: Dados da Pesquisa (2008). 
A relevância dos temas Inovação e Qualidade na pesquisa Contábil: Um estudo bibliométrico em eventos científicos no Brasil Jacquelline Aparecida Batista de Andrade, Cristiana Fernandes de Muÿlder

De todos os trabalhos que compunham as áreas temáticas verificadas no $17^{\circ}$ CBC, registrou-se 2.493 citações, com ampla predominância do termo qualidade que se apresenta com uma concentração 19 vezes maior em relação ao termo inovação.

Observou-se que três de todos os dez temas apresentados - Educação como Fator de Competência Profissional, O Processo de Comunicação das Informações Contábeis e o tema Livre representam juntos $81,45 \%$ das ocorrências dos termos Inovação e $74,08 \%$ de qualidade. Curiosamente no tema Livre se concentra a maior parte das citações em ambos os termos - Inovação (43,55\%) e Qualidade (56,14\%), revelando que a liberdade de escolha propiciou uma freqüência maior destes dois construtos.

Esta tendência pode confirmar a diversificação de funções indicada por Christo (2001) na área contábil e a busca por novas formas de trabalho que podem ser consideradas inovadoras.

\subsection{CBC - Congresso Brasileiro de Contabilidade de 2008}

A Tabela 2, a seguir, indica o número de artigos que apresentam os termos Inovação e Qualidade e a distribuição percentual em cada citação, dentre todos os

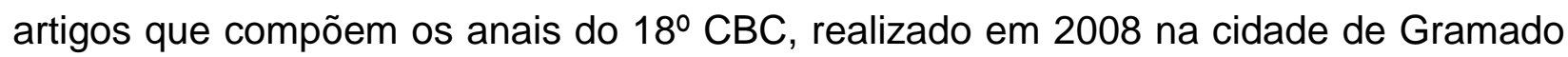
- RS. Este congresso teve como objetivo principal promover o aperfeiçoamento profissional por meio do incentivo ao desenvolvimento científico da área contábil, que traduz fielmente o seu lema: "Contabilidade: ciência a serviço do desenvolvimento. 
A relevância dos temas Inovação e Qualidade na pesquisa Contábil: Um estudo bibliométrico em eventos científicos no Brasil Jacquelline Aparecida Batista de Andrade, Cristiana Fernandes de Muÿlder

Tabela 2 - Número de Citações por Termo consultado

\begin{tabular}{|c|c|c|c|c|c|c|}
\hline \multirow[b]{2}{*}{ TERMO } & \multirow[b]{2}{*}{$\begin{array}{c}\text { № Total } \\
\text { de Artigos }\end{array}$} & \multicolumn{5}{|c|}{$18^{\circ} \mathrm{CBC}-2008$} \\
\hline & & $\begin{array}{c}\text { № de } \\
\text { Artigos } \\
\text { com } \\
\text { citações }\end{array}$ & $\begin{array}{c}\% \text { de } \\
\text { Artigos } \\
\text { com } \\
\text { citações }\end{array}$ & $\begin{array}{c}\text { № de } \\
\text { citações }\end{array}$ & $\begin{array}{c}\text { Média de } \\
\text { citações } \\
\text { por artigo }\end{array}$ & $\begin{array}{c}\text { № de } \\
\text { Artigos } \\
\text { acima da } \\
\text { média }\end{array}$ \\
\hline INOVAÇÃO & 99 & 19 & 19,19 & 30 & 1,58 & 5 \\
\hline QUALIDADE & 99 & 77 & 77,78 & 351 & 4,56 & 26 \\
\hline Total Geral & & 96 & 96,97 & 381 & 3,97 & \\
\hline
\end{tabular}

Fonte: Dados de Pesquisa (2008).

Analisando os dados da Tabela 2 sob a ótica da "Lei de Zipf" (freqüência de ocorrência de palavras em dado texto), percebe-se que de um total de 99 trabalhos apresentados no evento, sendo um artigo de Portugal, $77,78 \%$ estão voltados para o termo Qualidade, com uma média de 4,56 citações por artigo, bem superior ao termo Inovação que apresentou apenas uma média de 1,58 citações por artigo.

Estes resultados vêm confirmar que o termo Inovação, especificamente levandose em conta a produção do conhecimento científico acadêmico em contabilidade, ainda é incipiente. A qualidade, que se tornou uma das principais prioridades competitivas para as empresas, fez com que muitos pesquisadores, estudiosos e profissionais da contabilidade referenciassem o termo qualidade com bastante freqüência na produção dos artigos acadêmicos.

Este resultado confirma a idéia de Marshal Junior et al. (2005), que relaciona a qualidade com outras demandas em função do tipo do produto, perfil dos consumidores e vincula a inovação à estratégia empresarial.

Os mesmos dados supracitados foram analisados por Estado, conforme Tabela 3. 
A relevância dos temas Inovação e Qualidade na pesquisa Contábil: Um estudo bibliométrico em eventos científicos no Brasil Jacquelline Aparecida Batista de Andrade, Cristiana Fernandes de Muÿlder

Tabela 3 - Distribuição de artigos por Estado

\begin{tabular}{|c|c|c|c|c|c|}
\hline Estado & $\mathbf{F}$ & $\%$ & Estado & F & $\%$ \\
\hline Pará - PA & 3 & 3,06 & São Paulo - SP & 8 & 8,16 \\
\hline Rondônia - RO & 2 & 2,04 & Paraná-PR & 7 & 7,14 \\
\hline Bahia - BA & 5 & 5,10 & Santa Catarina - SC & 10 & 10,20 \\
\hline Ceará - CE & 1 & 1,02 & Rio Grande do Sul - RS & 13 & 13,27 \\
\hline Paraiba - PB & 5 & 5,10 & RJ/SP & 1 & 1,02 \\
\hline Pernanbuco - PE & 1 & 1,02 & SP/MT & 1 & 1,02 \\
\hline Rio Grande do Norte -RN & 2 & 2,04 & DF/SC & 2 & 2,04 \\
\hline Sergipe - SE & 2 & 2,04 & ES/SP & 1 & 1,02 \\
\hline Distrito Federal - DF & 3 & 3,06 & RN/RJ & 1 & 1,02 \\
\hline Goiás - GO & 2 & 2,04 & SP/SC & 1 & 1,02 \\
\hline Mato Grosso - MT & 1 & 1,02 & DF/PE & 1 & 1,02 \\
\hline Mato Grosso do Sul - MS & 1 & 1,02 & DF/AL/PE & 1 & 1,02 \\
\hline Espírito Santo - ES & 5 & 5,10 & RS/SC & 1 & 1,02 \\
\hline Minas Gerais - MG & 9 & 9,18 & & & \\
\hline Rio de Janeiro - RJ & 8 & 8,16 & Total & $\mathbf{9 8}$ & $\mathbf{1 0 0 , 0 0}$ \\
\hline
\end{tabular}

Fonte: Dados de Pesquisa (2008).

Como se verifica na análise, os estados das regiões Sul e Sudeste concentram $67,34 \%$ dos artigos selecionados na amostra, seguidos pela Região Nordeste (18,37\%), Centro-Oeste $(9,18 \%)$ e Norte $(5,10 \%)$, com destaque para os estados de Santa Catarina e Rio Grande do Sul que contribuíram com a publicação de 27 artigos dos 99 apresentados no $18^{\circ} \mathrm{CBC}$.

Tal concentração nos estados da região Sul e Sudeste se explica, pois, atualmente, segundo a CAPES (2011), existem 110 programas vinculados à Área de Administração, Ciências Contábeis e Turismo e apenas 18 referem-se à Contabilidade (Contabilidade, Ciências Contábeis e Controladoria). Destes, 9 em instituições de estados do sudeste, 4 da região Sul, 1 do Distrito Federal, 1 do Amazonas e 3 de estados do nordeste brasileiro, logo, as regiões Sul e Sudeste detém $72 \%$ dos programas da referida área.

A pesquisa também revelou que a região Sul e Sudeste, com os Estados de Minas Gerais, São Paulo, Rio de Janeiro, Santa Catarina, Paraná e Rio Grande do Sul, 
A relevância dos temas Inovação e Qualidade na pesquisa Contábil: Um estudo bibliométrico em eventos científicos no Brasil Jacquelline Aparecida Batista de Andrade, Cristiana Fernandes de Muÿlder

apresentou quantidade de artigos acima da média de citações dos termos Inovação e Qualidade, conforme se verifica na Tabela 4.

Tabela 4 - Estados com artigos acima da média

\begin{tabular}{|c|c|c|c|c|}
\hline \multirow{2}{*}{ Estado } & \multicolumn{4}{|c|}{ № de Artigos } \\
\cline { 2 - 5 } & Inovação & $\%$ & Qualidade & $\%$ \\
\hline Pará - PA & 0 & 0,00 & 2 & 7,69 \\
\hline Bahia - BA & 0 & 0,00 & 2 & 7,69 \\
\hline Paraíba - PB & 0 & 0,00 & 4 & 15,38 \\
\hline Distrito Federal - DF & 0 & 0,00 & 2 & 7,69 \\
\hline Goiás - GO & 0 & 0,00 & 1 & 3,85 \\
\hline Minas Gerais - MG & 1 & 20,00 & 2 & 7,69 \\
\hline Rio de Janeiro - RJ & 1 & 20,00 & 1 & 3,85 \\
\hline São Paulo - SP & 1 & 20,00 & 4 & 15,38 \\
\hline Paraná - PR & 0 & 0,00 & 2 & 7,69 \\
\hline Santa Catarina - SC & 1 & 20,00 & 5 & 19,23 \\
\hline Rio Grande do Sul - RS & 1 & 20,00 & 1 & 3,85 \\
\hline TOTAL & $\mathbf{5}$ & $\mathbf{1 0 0 , 0 0}$ & $\mathbf{2 6}$ & $\mathbf{1 0 0 , 0 0}$ \\
\hline
\end{tabular}

Fonte: Dados da Pesquisa (2008).

\subsection{EnANPAD 2007 e 2008}

O Encontro da Associação Nacional de Pós-Graduação e Pesquisa em Administração, o EnANPAD, considerado o maior evento do cenário brasileiro da administração, qualificado pelo sistema Qualis (Capes), com disseminação do conhecimento no campo das Ciências Administrativas e Contábeis, apresentou nos anos de 2007 e 2008 quase 2.000 artigos, sendo que deste total, 202 compreendem a área das Ciências Contábeis, o que corresponde a $10 \%$ de toda a produção acadêmica deste evento.

O universo pesquisado refere-se aos artigos apresentados na temática de Contabilidade para Usuários Externos, Contabilidade Gerencial e Ensino e Pesquisa em Contabilidade, conforme apresentado na Tabela 5, com destaque para a evidenciação dos termos Inovação e Qualidade existentes nos referidos artigos. 
A relevância dos temas Inovação e Qualidade na pesquisa Contábil: Um estudo bibliométrico em eventos científicos no Brasil Jacquelline Aparecida Batista de Andrade, Cristiana Fernandes de Muÿlder

Tabela 5 - Número de Citações por Área

\begin{tabular}{|c|c|c|c|c|c|}
\hline \multirow[b]{3}{*}{ ÁREA } & \multirow{3}{*}{$\begin{array}{c}\text { № Total } \\
\text { de } \\
\text { Artigos } \\
\text { na Área }\end{array}$} & \multicolumn{4}{|c|}{ EnANPAD 2007} \\
\hline & & \multicolumn{2}{|c|}{ INOVAÇÃO } & \multicolumn{2}{|c|}{ QUALIDADE } \\
\hline & & $\begin{array}{c}\text { № de } \\
\text { Artigos } \\
\text { com } \\
\text { citações }\end{array}$ & $\begin{array}{c}\% \text { de } \\
\text { Artigos } \\
\text { com } \\
\text { citações }\end{array}$ & $\begin{array}{c}\text { № de } \\
\text { Artigos } \\
\text { com } \\
\text { citações }\end{array}$ & $\begin{array}{c}\% \text { de } \\
\text { Artigos } \\
\text { com } \\
\text { citações }\end{array}$ \\
\hline Contabilidade para Usuários Externos & 56 & 4 & 7,14 & 39 & 69,64 \\
\hline Contabilidade Gerencial & 38 & 16 & 42,11 & 32 & 84,21 \\
\hline Ensino e Pesquisa em Contabilidade & 18 & 4 & 22,22 & 15 & 83,33 \\
\hline Total & 112 & 24 & 21,43 & 86 & 76,79 \\
\hline \multirow[b]{3}{*}{ ÁREA } & \multirow{3}{*}{$\begin{array}{c}\text { № Total } \\
\text { de } \\
\text { Artigos } \\
\text { na Área }\end{array}$} & \multicolumn{4}{|c|}{ EnANPAD 2008} \\
\hline & & \multicolumn{2}{|c|}{ INOVAÇÃO } & \multicolumn{2}{|c|}{ QUALIDADE } \\
\hline & & $\begin{array}{c}\text { № de } \\
\text { Artigos } \\
\text { com } \\
\text { citações }\end{array}$ & $\begin{array}{c}\text { \% de } \\
\text { Artigos } \\
\text { com } \\
\text { citações }\end{array}$ & $\begin{array}{c}\text { № de } \\
\text { Artigos } \\
\text { com } \\
\text { citações }\end{array}$ & $\begin{array}{c}\% \text { de } \\
\text { Artigos } \\
\text { com } \\
\text { citações }\end{array}$ \\
\hline Contabilidade para Usuários Externos & 44 & 5 & 11,36 & 29 & 65,91 \\
\hline Contabilidade Gerencial & 26 & 11 & 42,31 & 20 & 76,92 \\
\hline Ensino e Pesquisa em Contabilidade & 20 & 6 & 30,00 & 15 & 75,00 \\
\hline Total & 90 & 22 & 24,44 & 64 & 71,11 \\
\hline
\end{tabular}

Fonte: Dados de Pesquisa (2008).

Os resultados indicam que o número de ocorrências de citações por artigo se concentra na área de Contabilidade Gerencial, nos períodos analisados, tanto para 0 termo Inovação; 42,11\% em 2007 e 42,31\% em 2008, quanto para o termo Qualidade, 84,21\% em 2007 e 76,92\% em 2008, apesar de ter ocorrido uma queda do total do número de artigos apresentados da área de contabilidade em quase 20\% de 2007 para 2008.

Em seguida tem-se a área de Contabilidade para Usuários Externos, que tem se expandido nos últimos anos no Brasil, em razão de várias mudanças econômicas e sociais que provocam uma discussão entre os pesquisadores e estudiosos da área, principalmente focados na qualidade da informação contábil. Isso é corroborado pelos 
A relevância dos temas Inovação e Qualidade na pesquisa Contábil: Um estudo bibliométrico em eventos científicos no Brasil Jacquelline Aparecida Batista de Andrade, Cristiana Fernandes de Muÿlder

números apresentados, uma vez que exatamente a metade dos artigos, coincidentemente nos dois períodos apresentados, pertence a esta área representando 69,64 \% dos artigos com citações deste termo em 2007 e 65,91\% em 2008.

Analisou-se, ainda, a média de citações dos artigos por área, como evidenciado na Tabela 6.

Tabela 6 - Média de Citações por Área

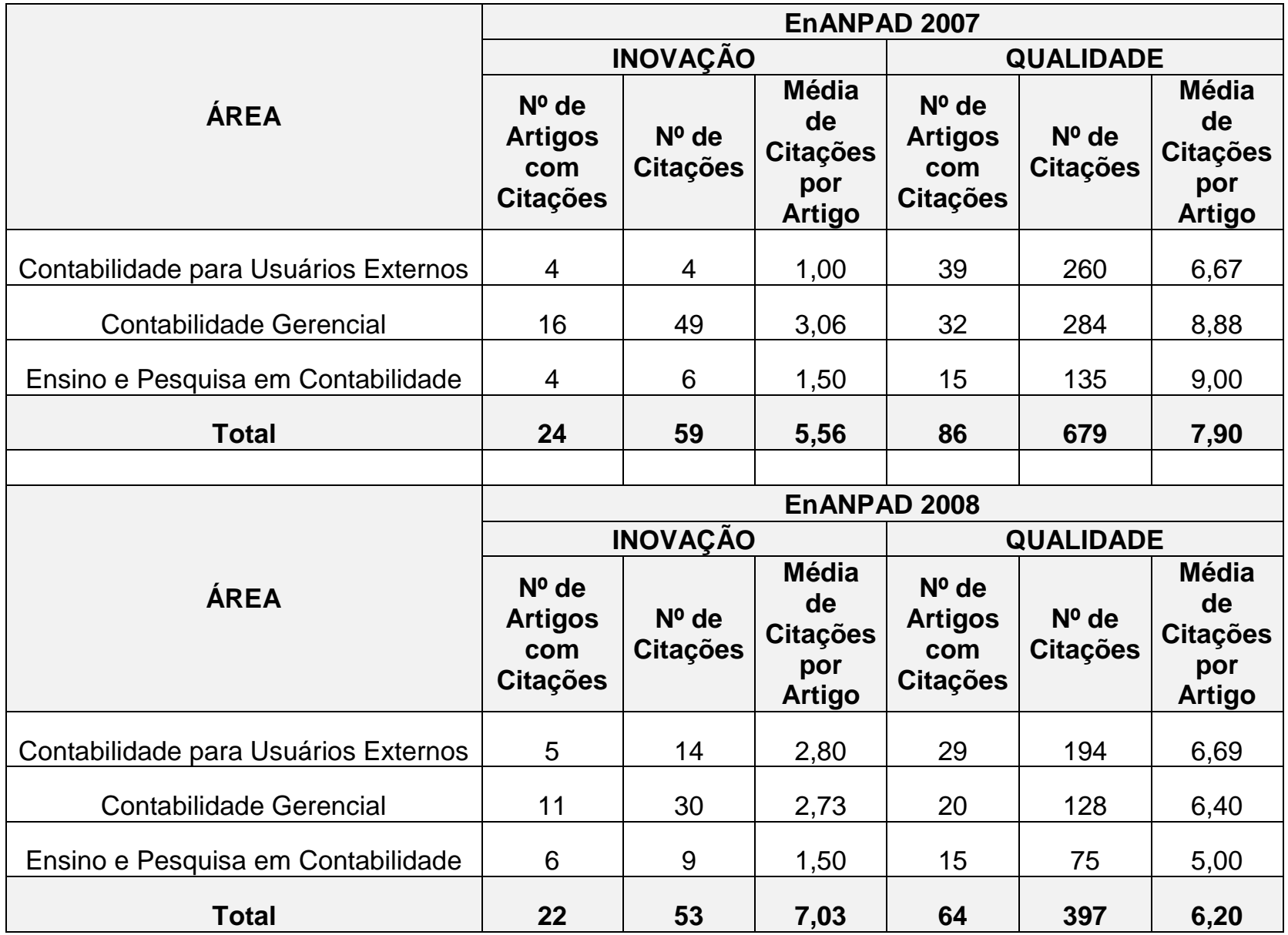

Fonte: Dados de Pesquisa (2008).

Observou-se uma aproximação na quantidade de artigos com citações, bem como uma uniformidade na média de citações por artigo na área de Contabilidade para Usuários Externos, presente nas ocorrências do termo Qualidade, em 2007 e 2008, 
A relevância dos temas Inovação e Qualidade na pesquisa Contábil: Um estudo bibliométrico em eventos científicos no Brasil

Jacquelline Aparecida Batista de Andrade, Cristiana Fernandes de Muÿlder

enquanto o termo Inovação apresenta-se uniforme em sua totalidade na temática de Ensino e Pesquisa em Contabilidade, com uma média de 1,5 de citações por artigo.

Os dados revelam que a ocorrência mais freqüente na média de citações por artigo continua com a Contabilidade Gerencial, tanto para o termo Inovação como Qualidade o que é esperado pelo fato do número maior de citações se concentrarem também nesta área.

\section{CONSIDERAÇÕES FINAIS}

Diante de discussões acerca de um cenário organizacional competitivo, onde a sobrevivência das empresas depende da atuação da área contábil que é primordial como ferramenta de decisão gerencial, logo se percebe a realização de estudos envolvendo as temáticas qualidade e inovação nesta área e o principal objetivo deste artigo foi verificar a inserção destes dois temas: Inovação e Qualidade na área contábil e sua evolução no meio acadêmico.

Por meio de pesquisa bibliométrica, foram analisadas as ocorrências dos termos nos trabalhos científicos nos principais eventos da área acadêmica: Congresso Brasileiro de Contabilidade 2004 (fase 1) e 2008 (fase 2) e, no Encontro Nacional da Associação Nacional de Pós-Graduação e Pesquisa em Administração (EnANPAD) 2007 (fase 3) e 2008 (fase 4) na área específica de Contabilidade.

Foram pesquisados na fase $1\left(17^{\circ} \mathrm{CBC}\right)$ todos os 10 temas apresentados no evento, sendo analisadas 2.493 citações, encontrando uma maior concentração do termo qualidade, representando 19 vezes as ocorrências do termo inovação.

Observou-se ainda que os temas Educação como Fator de Competência Profissional, O Processo de Comunicação das Informações Contábeis e o tema Livre representaram juntos $81,45 \%$ das ocorrências do termo inovação e $74,07 \%$ das ocorrências do termo qualidade, sendo o tema Livre, curiosamente, o que mais pesa nas duas análises. 
A relevância dos temas Inovação e Qualidade na pesquisa Contábil: Um estudo bibliométrico em eventos científicos no Brasil Jacquelline Aparecida Batista de Andrade, Cristiana Fernandes de Muÿlder

Respondendo aos objetivos da pesquisa, tendo como base à "Lei de Zipf", verificou-se na fase 2 (18을 $\mathrm{CBC}$ ), que $77,78 \%$ dos artigos apresentados neste evento, estão voltados ao termo Qualidade, com uma média de citações por artigo 2,89 vezes maior, quando comparado com o termo Inovação, que juntos compõem o total dos 99 trabalhos apresentados. Isso confirma no universo científico da contabilidade, que o termo inovação ainda é incipiente, ao contrário do termo qualidade que tem sido bastante referenciado na produção dos artigos acadêmicos.

No que diz respeito à distribuição dos artigos por estado, merece destaque a região Sul, notadamente os estados de Santa Catarina e Rio Grande do Sul, com distribuição de artigos bem acima da média, denotando indícios de uma detenção maior da produção acadêmica atual na área de contabilidade para esta região, com um peso maior para a Qualidade.

Surpreende a grande ocorrência de artigos voltados à área das Ciências Contábeis nos anais do EnANPAD 2007 (fase 3) e 2008 (fase 4), que totaliza 10\% de toda a produção acadêmica deste evento, ainda que com uma redução de 22 trabalhos apresentados no ano de 2008 em relação a 2007.

Vale ressaltar a uniformidade na média de citações por artigo nestes dois eventos, presente tanto para o termo Inovação quanto o de Qualidade, com uma concentração na área de Contabilidade Gerencial, deduzindo que se começa a explorar mais a contabilidade neste campo. Conforme Louderback et al. (2000), além de tratar de eventos econômicos tal como a contabilidade financeira, a contabilidade gerencial se adapta às mudanças tecnológicas, as modificações nas necessidades dos gestores e novas abordagens das outras áreas funcionais dos negócios, provendo de informações a estes mesmos gestores internos das organizações, dando condições de entender, planejar e até mesmo prever o futuro.

Pode-se ainda confirmar que existe, como mencionam Christo (2001) e Marshal Junior et al. (2005), um interesse de pesquisa em qualidade e está relacionada à inovação e estratégia frente às demandas em função do tipo de produto, perfil de consumidor. 
A relevância dos temas Inovação e Qualidade na pesquisa Contábil: Um estudo bibliométrico em eventos científicos no Brasil Jacquelline Aparecida Batista de Andrade, Cristiana Fernandes de Muÿlder

\section{REFERÊNCIAS}

ANDRADE, M. M. (2006). Introdução à metodologia do trabalho científico. (7 ed.). São Paulo: Ed. Atlas.

ARAÚJO, C.A. (2006). Bibliometria: evolução histórica e questões atuais. Porto Alegre: Em Questão, v. 12, n. 1, p. 11-32, jan./jun.

CARDOSO, R.L; MENDONÇA NETO, O.R.; RICCIO, E.L.; SAKATA, M.C.G. (2005). Pesquisa Científica em Contabilidade entre 1990 e 2003. Revista de Administração de Empresa, v. 45, n.2, Abril/Junho.

CARDOSO, R.L.; PEREIRA, C.A.; GUERREIRO, R. (2004). A produção acadêmica em Custos no âmbito do EnANPAD: uma análise de 1998 a 2003. In: ENCONTRO ANUAL DA ASSOCIAÇÃO NACIONAL DE PÓS-GRADUAÇÃO E PESQUISA EM ADMNISTRAÇÃO, 28. Curitiba. Anais... Curitiba: ANPAD.

CHRISTO, A. R. (2001). Qualidade percebida nos serviços de atendimento bancários em agências do Banco do Estado do Espírito Santo (Banestes S/A) da Grande VitóriaES. Belo Horizonte. (Dissertação de Mestrado). Centro de Pós-Graduação em Administração da Faculdade de Ciências Econômicas da Universidade Federal de Minas Gerais - UFMG.

CUNHA, J.V.A., MARTINS, G.A.; JR, E.B.C. (2008). Teses em Ciências Contábeis: Uma análise de sua propagação. In: ENCONTRO ANUAL DA ASSOCIAÇÃO NACIONAL DE PÓS-GRADUAÇẢO E PESQUISA EM ADMINISTRAÇÃO, 32. Rio de Janeiro. Anais... Rio de Janeiro: ANPAD.

FARO, M.C.S.C., SILVA, R.N.S. (2008). A Natureza da Pesquisa em Contabilidade Gerencial - Análise Bibliométrica de 1997 a 2007 nos Principais Periódicos Internacionais. In: ENCONTRO ANUAL DA ASSOCIAÇÃO NACIONAL DE PÓSGRADUAÇÀO E PESQUISA EM ADMNISTRAÇÃO, 32. Rio de Janeiro. Anais... Rio de Janeiro: ANPAD.

GIL, A. C. (2007). Como elaborar Projetos de Pesquisa. (4 ed.). São Paulo: Ed. Atlas.

GOMES, C. A.S., OLIVEIRA, J.R.S., COELHO, N. S., ANDRADE, C.C.B.M. (2008). Produção Científica em Contabilidade Pública: uma Análise dos Artigos Apresentados no EnANPAD e Congresso USP de Controladoria e Contabillidade no Período 20042007. In: ENCONTRO ANUAL DA ASSOCIAÇÃO NACIONAL DE PÓS-GRADUAÇÀO E PESQUISA EM ADMNISTRAÇÃO, 32. Rio de Janeiro. Anais... Rio de Janeiro: ANPAD. 
A relevância dos temas Inovação e Qualidade na pesquisa Contábil: Um estudo bibliométrico em eventos científicos no Brasil Jacquelline Aparecida Batista de Andrade, Cristiana Fernandes de Muÿlder

GUEDES, V. L.S.; BORSCHIVER, S. (2005). Bibliometria: uma ferramenta estatística para a gestão da informação e do conhecimento, em sistemas de informação, de comunicação e de avaliação científica e tecnológica. Disponível em: <htpp://dici.ibict.br/archive/00000508/>. Acesso em: 02/out/2008.

LEITE FILHO, G.A. (2005). Padrões de produtividade de autores em periódicos e congressos na área de Contabilidade no Brasil: Um estudo Bibliométrico. In: CONGRESSO USP DE CONTROLADORIA E CONTABILIDADE, 5. São Paulo. Anais... São Paulo: FEA/USP.

LOUDERBACK, J.G.; HOLMEN, J.; DOMINIAK, G. (2000). Managerial accounting. (9th edition). Cincinnati: South-Western College Publ.

MACIAS-CHAPULA, C.A. (1998). O papel da informetria e da cienciometria e sua perspectiva Nacional e internacional. Brasília: Ciência da Informação, v. 27, n.2, p. 134140, maio/ago.

MARSHALL JUNIOR, I.; CIERCO, A. A.; ROCHA, A. V.; MOTA, E. B.; AMORIM, S. R. L. (2006). Gestão da Qualidade. (8 ed.). Rio de Janeiro: Editora FGV. v. 1. 196 p.

MARTINS, G. de A.; SILVA, R. B. C. da. (2005). Plataforma Teórica - Trabalhos do $3^{\circ}$. E 4․ Congressos USP de Controladoria e Contabilidade: Um Estudo Bibliométrico. In: CONGRESSO USP DE CONTROLADORIA E CONTABILIDADE, 5. São Paulo. Anais... São Paulo: FEA/USP.

MARTINS, G. de A.; THEÓPHILO, C. R. (2007). Metodologia da Investigação Científica para Ciências Sociais Aplicadas. São Paulo: Atlas.

PERIN, G.M., SAMPAIO, H.C., HOOLEU, G. (2007). Impacto dos Recursos da empresa na Performance da Organização. Revista de Administração de Empresa, v. 47, n. 4, p. 46-58.

QUEIROZ, A. C. S. (2007). Modelos Organizacionais para Inovação. In: Moreira, D. M.; Queiroz, A. C. S.. (Orgs.). Inovação Organizacional e Tecnológica. (1 ed.). São Paulo: Thomson. p. 79-98.

SCHUMPETER, J.A. (1982). A Teoria do Desenvolvimento Econômico. (3 ed.). São Paulo: Abril Cultural.

SILVA, A. C. B; OLIVEIRA, E. C. De; RIBEIRO FILHO, J. F. (2005). Revista Contabilidade e Finanças USP: uma comparação entre os períodos 1989/2001 e 2001/2004. Revista Contabilidade e Finanças - USP. São Paulo, n. 39, p.20-32, Set/Dez. 
A relevância dos temas Inovação e Qualidade na pesquisa Contábil: Um estudo bibliométrico em eventos científicos no Brasil

Jacquelline Aparecida Batista de Andrade, Cristiana Fernandes de Muÿlder

THEOPHILO, C. R; IUDÍCIBUS, S. de. (2005). Uma análise crítico-epistemológica da produção científica em Contabilidade no Brasil. In: ENCONTRO ANUAL DA ASSOCIAÇÃO NACIONAL DE PÓS-GRADUAÇÀO E PESQUISA EM ADMNISTRAÇÃO, 29., 2005. Brasília. Anais... Brasília: ANPAD.

Data de Submissão: 14/05/2009

Data de Aceite: 29/11/2010 